\title{
Methyl Isothiocyanate Residential Community Air Assessment for South Franklin County, Washington
}

\author{
J. H. Merriman · V. R. Hebert
}

Published online: 28 February 2007

(C) Springer Science+Business Media, LLC 2007

Metam sodium (metam; sodium methyl-dithiocarbamate) by weight is the most widely used soil fumigant, and the third most used pesticide in the United States (57-62 million lb/year) (USEPA, 2005a). Metam is applied preplant to a wide variety of crops, with potatoes, tomatoes, tobacco, and strawberries receiving more than 1 million pounds annually.

Metam rapidly hydrolyzes upon contact with soil moisture to methyl isothiocyanate (MITC), the biologically active ingredient. The high vapor pressure of MITC $\left(2.5-2.8 \mathrm{kPa}\right.$ at $\left.20^{\circ} \mathrm{C}\right)$ can lead to substantial surface emission and subsequent off-target air mass movement if metam is not properly applied to the soil (Lee et al., 2002; Li et al., 2006; Sullivan et al., 2004). Thus, MITC may present a significant human inhalation exposure pathway in communities at the urbanagricultural interface (USEPA, 2005b).

Methyl isothiocyanate is an acute respiratory irritant (Pruett et al., 2001). Many residential exposure incidences with reported nose irritation, sore throat, nausea, and dizziness from probable MITC exposure have been well documented in California (Thongsinthusak, 2003). Although not classified by the EPA as a hazardous air pollutant, MITC is considered a toxic air contaminant under the Code of California Regulations, Title 3, Section 6890(b).

In Washington State, metam is the most widely used fumigant, with more than 20 million pounds applied in 2005 for control of soil-borne nematodes and diseases in large-scale potato production (NASS, 2006). It is

J. H. Merriman · V. R. Hebert ( $₫)$

Washington State University Tri-Cities,

2710 University Drive, Richland, WA 99354-1671, USA

e-mail: vhebert@tricity.wsu.edu typically applied preplant during the fall by center-pivot chemigation (PMSP, 2002). Recent expansion of suburban development into traditionally agricultural areas now appears to be associated with an increasing number of residential health complaints. Recently, 12 cases of possible or probable acute illnesses related to MITC inhalation exposure have been reported to the Washington State Department of Health (Burgess et al., 2000; Morrissey, 2006). Data on methyl isothiocyanate concentration in residential air are lacking for estimation of possible inhalation exposure near potatogrowing regions in Eastern Washington.

A few agricultural air monitoring studies have evaluated off-target movement of MITC to residential communities. The majority of these evaluations have been conducted in California near row crop production operations (California Air Resources Board, 1994; California Department of Pesticide Regulations, 2003; Seiber et al., 1999). In particular, Seiber et al. (1999) studied regional off-site movement of MITC to residential areas in Bakersfield, California during the summer fumigation season in this region. The 1-h timeweighted average (TWA) MITC residential outdoor ambient concentrations ranged from 0.3 parts per billion ( $\mathrm{ppb}$ ) to a maximum of $14 \mathrm{ppb}$. Thongsinthusak (2003) has comprehensively summarized the MITC concentrations found in the California residential studies. Fumigation practices for Pacific Northwest field crops differ appreciably from those used for California row crops. Whereas metam is typically shanked directly into the soil during the spring or summer in California, it is generally applied by center-pivot chemigations in eastern Washington during the cooler fall months of September and October before irrigation districts shut off water supplies. The intensity of 


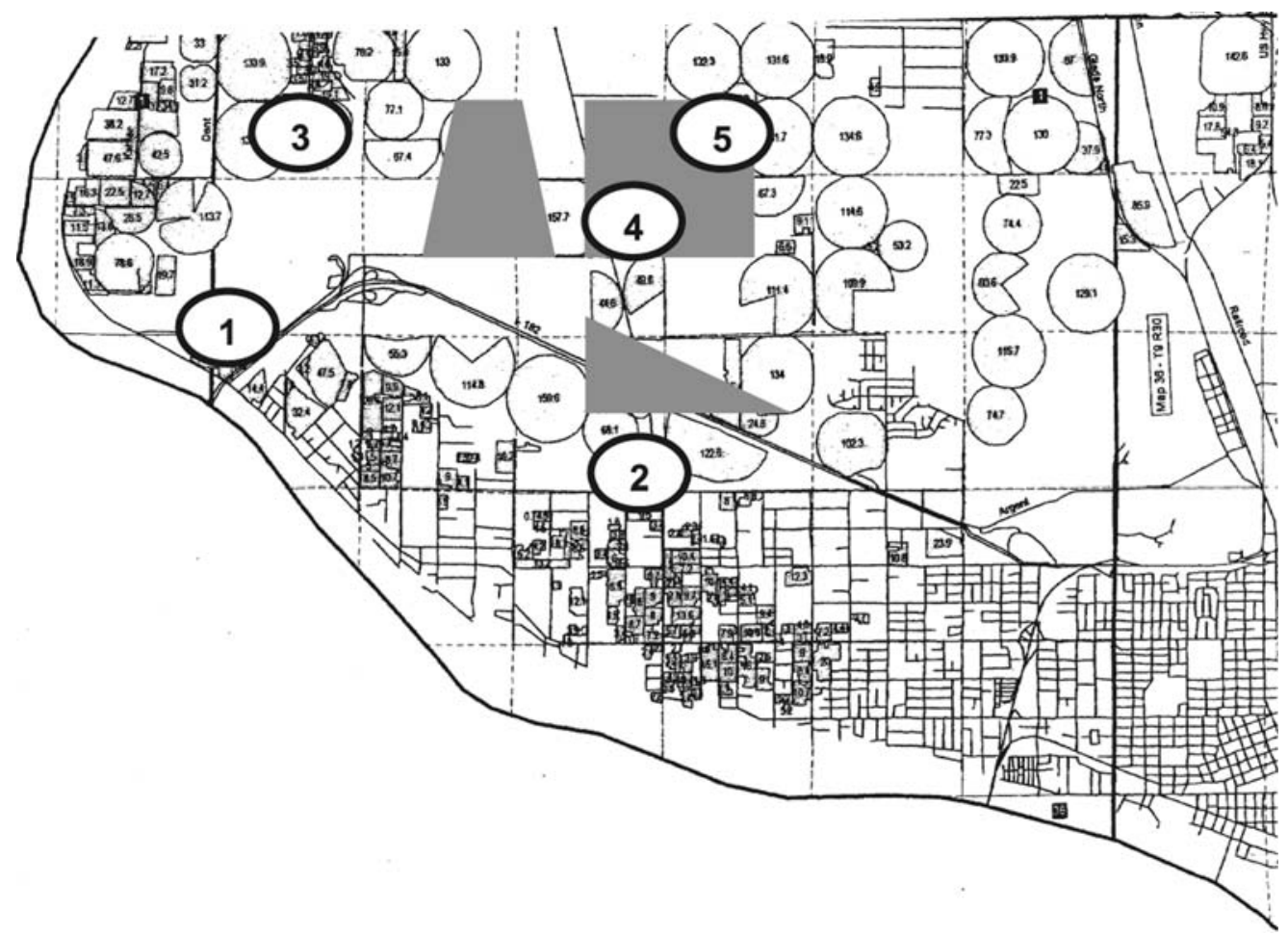

Fig. 1 Residential air monitoring locations in relation to crop circles. Shaded areas represent residential expansion since 2002. From Franklin County Atlas. Franklin Conservation District (2003)

chemigations conducted during this period, inadequate preapplication soil preparation, and insufficient watering at application are factors thought to be contributing to off-target MITC air mass movement to Pacific Northwest residential communities.

South Franklin County in Eastern Washington is representative of an agriculturally important region currently facing rapid residential growth into traditionally agricultural areas. Recently, many housing developments and commercial buildings have been built adjacent to active potato-growing fields, thus increasing the potential for residential inhalation exposure to MITC. No data had been gathered on the ambient air concentration of MITC in this and other residential communities adjacent to actively fumigated fields in Washington State. To address public health concerns, we conducted an ambient air monitoring study in south Franklin County in the fall of 2005. This monitoring study was designed to establish baseline fumigant air emission information for human health risk assessment.

\section{Materials and Methods}

Methyl isothiocyanate was monitored in ambient air near residential and commercial buildings in south
Franklin County during the fall fumigation season between September 26, 2005 and October 25, 2005. Weather data were collected at the Columbia Basin College, Pasco, Washington. This weather station was within 5 miles of the sampling site locations. Weather data describing soil and air temperatures, wind velocity, and precipitation over the 31-day study interval are publicly accessible in a technical summary report (FEQL, 2006). Four air monitoring sites were selected: three residential and one commercial. An additional residential site was added later in the study (Fig. 1).

Data were collected from stations 1 through 4, starting the first day of the monitoring study. Station 5 monitoring started five sampling days thereafter. The residents at stations 1 and 2 asked to be dismissed from the study after the 20th sampling interval date. For each location, a sampling mast was constructed that consisted of an air sampling unit (SKC HiLite series, Fullerton, CA) placed at the base of a ring stand with a vertical $1-\mathrm{m}$ crossbar. Tubing with a 0.375 -in. interior diameter (C-Flex; Cole-Palmer, Vernon Hills IA, USA) was used to split the flow to 1-g charcoal-filled glass cartridges (SKC West, Fullerton, CA) co-located at each end of the crossbar. The AC powered sampling unit pumped air at approximately $5 \mathrm{~L} / \mathrm{min}$. Actual flows for each sampling cartridge were recorded at the 
Table 1 Storage stability, laboratory, and field fortification evaluations

\begin{tabular}{llllll}
\hline & $\begin{array}{l}\text { Days in } \\
\text { storage }\end{array}$ & $\begin{array}{l}\text { Solution concentration } \\
\text { in } 5 \mathrm{~mL}(\mu \mathrm{g} / \mathrm{mL})\end{array}$ & $\begin{array}{l}\text { Recovery } \\
\text { range }(\%)\end{array}$ & $\begin{array}{l}\text { Average } \\
\text { recover }(\%)\end{array}$ & $\begin{array}{l}\text { SD } \\
\text { analyses }\end{array}$ \\
\hline Storage stability & 0 & 1.0 & $103-106$ & 104 & 3 \\
& 14 & 1.0 & $121-138$ & 128 & 2 \\
Lab fortification & 85 & 1.0 & $95-109$ & 102 & 9 \\
& NA & 0.5 & $109-113$ & 111 & 7 \\
Field fortification & NA & 4.0 & $109-114$ & 111 & 3 \\
\hline
\end{tabular}

start and end of each sampling period using calibrated rotameters. The average of the 2-point rotameter flow readings and sampling duration were used to calculate the volume of air sampled in cubic meters. Each sampling period was for $24 \mathrm{~h}$ and comprised two 12-h day and evening subsampling intervals.

Field fortifications were performed routinely over the course of the monitoring study. Each field fortification was prepared by injecting $50 \mu \mathrm{L}$ of a $100-\mu \mathrm{g} / \mathrm{mL}$ solution (i.e., $5 \mu \mathrm{g}$ MITC) into the cartridge before placement in the field. The field fortification spike was co-located with a charcoal cartridge sampling of residential ambient air over the approximate 12-h sampling interval. After each sampling interval, the charcoal sampling cartridges were immediately transferred to the Food and Environmental Quality Laboratory (FEQL), Washington State University, where they were placed in frozen storage at $-80^{\circ} \mathrm{C}$. Trip blanks routinely accompanied the sample shipment.

An analytical method based on California Department of Pesticide Regulations (California Department of Pesticide Regulations, 1994) was developed and validated for determining MITC in the charcoal sampling tubes. The 1-g charcoal media was removed from the glass cartridge, and solvent was extracted using 5 $\mathrm{mL}$ of a 1:4 mixture of carbon disulfide and ethyl acetate with sonication. The extract was filtered through a $0.45-\mu \mathrm{m}$ Teflon membrane, then vialed for gas chromatography determination. A Varian Star 3400CX gas chromatograph (Walnut Creek, CA) using thermionic-specific detection (TSD) with the 8200CX Autosampler (Walnut Creek, CA) was used for residue detection and quantification. A $15-\mathrm{m} \times 0.53-\mathrm{mm}, 1-\mu \mathrm{m}-$ film-thickness Agilent DB-1701 chomatographic column (Santa Clara, CA) was used for analyte separation, with ultrapure helium serving as the carrier gas. The initial column temperature of $55^{\circ} \mathrm{C}$ was ramped to $80^{\circ} \mathrm{C}$ by $5^{\circ} \mathrm{C} / \mathrm{min}$ increments and held for $6 \mathrm{~min}$. The hydrogen, air, and makeup gas flows were set at 3 to 4
$\mathrm{mL} / \mathrm{min}, 100$ to $120 \mathrm{~mL} / \mathrm{min}$, and 25 to $30 \mathrm{~mL} / \mathrm{min}$, respectively, over the course of the study. The MITC retention time was approximately $3.6 \mathrm{~min}$.

Integration of MITC peak areas was performed using Varian Star Chromatography Workstation software (Walnut Creek, CA). For quality control during the gas chromatography operation, a laboratory matrix control and matrix-fortified sample accompanied each analytical set. All residue samples were bracketed with external calibration standards. For each analytical set, at least four linearity standards were used in the calculation of the linear regression curve using a spreadsheet program (Microsoft Excel, Redman, WA). Residues (in $\mu \mathrm{g} / \mathrm{m}^{3}$ ) were calculated on the basis of external standard calibration using linear regression and total air volume sampled. The method limit of quantitation was estimated to be $0.1 \mu \mathrm{g} / \mathrm{m}^{3}$ ( $\left.\sim .03 \mathrm{ppb}\right)$, with a method limit of detection of $0.03 \mu \mathrm{g} / \mathrm{m}^{3}(\sim 0.01$ $\mathrm{ppb}$ ) based on a 12-h air sampling interval at $5 \mathrm{~L} / \mathrm{min}$.

Charcoal cartridges were fortified with known MITC concentrations for evaluation of field/laboratory percentage recoveries and the potential for breakthrough over the 12-h sampling interval. Before performance of MITC residue determinations, a method validation set was performed to demonstrate MITC extraction efficacy (in triplicate) from the $1-\mathrm{g}$ charcoal cartridges. The average recoveries of spiked cartridges ranging from a total of 2.5 to $250 \mu \mathrm{g}$ MITC are presented in Table 1 . A $-80^{\circ} \mathrm{C}$ storage stability evaluation for MITC on charcoal-filled glass cartridges was completed for this study covering a storage interval of 85 days. A series of nine blank 1-g charcoal-filled glass cartridges were fortified with $5 \mu \mathrm{g}$ of MITC, then placed in a $-80^{\circ} \mathrm{C}$ freezer. Three of these were evaluated at 0-, 14-, and 85-day intervals (Table 1). All samples for this study were analyzed within the 85-day frozen storage interval. A more descriptive account of field and analytical quality control for this air monitoring study can be found in FEQL (2006). 


\section{Results and Discussion}

The analytical method for measuring MITC was found to be reliable and was validated in triplicate from laboratory fortifications on 1-g charcoal cartridges at a total MITC of 2.5, 20, 50, and $250 \mu \mathrm{g}$ before the field samples were analyzed. The average MITC recovery from laboratory fortifications performed with each analytical sample set was $96 \% \pm 13 \%$. Methyl isothiocyanate was found to be stable under $-80^{\circ} \mathrm{C}$ cold storage for a period of 85 days (Table 1). Methyl isothiocyanate recovery averaged $67 \%$ from charcoal cartridges spiked with $5 \mu \mathrm{g}$ and placed in the field during the 12-h sampling period (Table 1).

The average fortified field recovery data could not be reliably used for residue data correction/adjustment because MITC residues in a number of air samples were greater than the field fortification spiking concentration. Methyl isothiocyanate residues above the limit of detection $(0.01 \mathrm{ppb})$ were detected in 199 of the 201 air samples collected at the five air monitoring site locations (Fig. 2). The 12-h TWA observed maximum air concentration was $67 \mu \mathrm{g} / \mathrm{m}^{3}$ (22 ppb), and the TWA concentration over the sampling time frame was approximately $10 \mu \mathrm{g} / \mathrm{m}^{3}$ (3.3 ppb in air). A major rain event during the first week of sampling coincided with the lowest MITC concentrations. Increasingly higher MITC air concentrations were observed in late October near the irrigation cutoff date. We terminated the study on October 25, one day after the irrigation water was cut off in south Franklin County.

Figure 2 also illustrates the general uniformity in MITC air concentrations observed among all locations on most of the interval sampling dates. Although we were unable to attain individual pesticide applicator records, we observed many field chemigations occurring over a brief period in the fall before the irrigation district's watering cutoff date. The intensity of chemigations occurring over the fall fumigation season in this area may contribute to the observed region-wide and fairly uniform air mass contamination. Of the air monitoring studies that have been performed to assess residential MITC emissions, that of Seiber et al. (1999) also observed a general air mass contamination over a large geographic area from multiple agricultural MITC source contributions.

In our monitoring study, the observed TWA 12-h maximum residue concentration of $22 \mathrm{ppb}$ was equivalent to California EPA's (Cal EPA) acute Reference Exposure Level (REL) and the EPA Office of Pesticide Protection's (OPP) human equivalent concentration (HEC) value. Both Cal EPA and OPP use the same data and toxicologic end points from the same human eye irritation study for purposes of estimating acute inhalation risk (USEPA, 2005b).
Fig. 2 Methyl isothiocyanate (MITC) in residential ambient air from September 25 to October 25, 2005, South Franklin County, Washington. Sites 1 and 2 were terminated three sampling interval dates before the end of the study

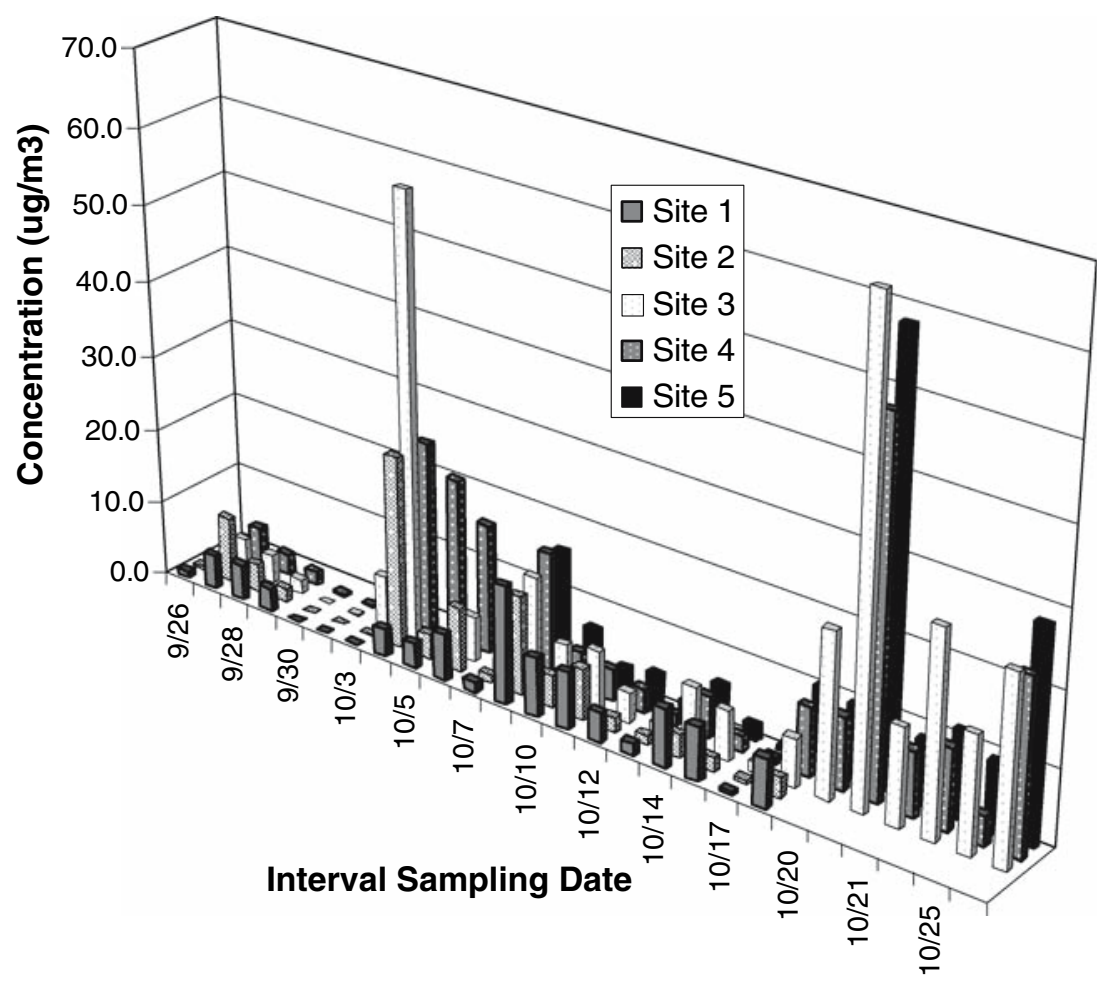


The observed TWA 30-day MITC air concentration of $3.3 \mathrm{ppb}$, however, exceeded the Cal EPA subchronic REL value of $1 \mathrm{ppb}$, but was less than the OPP $5 \mathrm{ppb}$ HEC value for short and intermediate-term inhalation. Cal EPA and OPP selected the same rodent 28-day subchronic inhalation exposure study to estimate reference doses, but each agency chose a different response threshold to estimate their regulatory levels of concern. Nevertheless, the results of our air monitoring assessment indicated that residential air concentrations of MITC may exceed acute and subchronic regulatory public health criteria.

In summary, recovery of MITC in numerous air samples collected in Franklin County, Washington shows that residential exposure occurs during the fall fumigation season. The maximum TWA residues can exceed levels of concern established by regulatory agencies for acute and/or subchronic inhalational exposure. Furthermore, comparatively high MITC air concentrations found near the end of the study period suggest that residential exposure may continue past the irrigation cutoff date. When the potential for residential exposure is assessed, MITC emissions should be studied over a longer period during the fall potato fumigation season.

Acknowledgments We thank Jane LePage and Dr. Allan Felsot from the WSU Food and Environmental Quality Laboratory for editorial review and data quality assurance, and Dr. Richard Fenske, School of Public Health and Community Medicine, University of Washington, for advice and air sampling equipment.

\section{References}

Burgess J, Morrissey B, Keifer MC, Robertson WO (2000) Fumigant-related illnesses: Washington State five-year experience. Clin Toxicol 38: 7-14

California Air Resources Board (1994) Ambient air monitoring for MITC in Kern County during summer 1993. Engineering Evaluation Branch, Monitoring Laboratory Division, Air Resources Board. No. C92-070

California Department of Pesticide Regulations (1994) Air monitoring for methyl isothiocyanate during a sprinkler application of metam-sodium. Report EH 94-02
California Department of Pesticide Regulations (2003) Ambient air monitoring for pesticides in Lompoc, California. Vol 2. Fumigants EH03-02

Food and Environmental Quality Laboratory (2006) MITC residential community air assessment: South Franklin Co, Washington. Analy Sum Rep FEQL-NG-0605. Accessed at: http://www.feql.wsu.edu/regsci.htm. Cited 15 May 2006

Lee S, McLaughlin R, Harnly M, Gunier R, Kreutzer R (2002) Community exposures to airborne agricultural pesticides in California: Ranking of inhalation risks. Environ Health Perspec 110: 1175-1184

Li L, Barry T, Mongar K, Wofford P (2006) Modeling methyl isothiocyanate soil flux and emission ratio form a field following a chemigation of metam-sodium. J Environ Qual 35: 707-713

Morrissey B (2006) USEPA. USEPA Docket ID Number EPA-HQ-OPP-2005-0125-0047 Accessed at http://www. regulations.gov/fdmspublic/component/main. Cited 15 May 2006

NASS (2006) Agricultural chemical usage 2005 field crop summary. Accessed at http://www.usda.mannlib.cornell.edu/ usda/nass/AgriChemUsFC//2000s/2006/AgriChemUsFC-0517-2006.pdf. Cited 15 May 2006

PMSP (2002) Pest management strategic plan for Pacific Northwest potato production. Accessed at http://www.ipmcenters.org/pmsp/pdf/PNWPotatoPMSP.pdf. Cited 15 May 2006

Pruett SB, Myers LP, Keil DE (2001) Toxicology of metam sodium. J Toxicol Environ Health 4: 207-222

Seiber JN, Woodrow JE, Krieger RI, Dinoff T (1999) Determination of ambient MITC residues in indoor and outdoor air in townships near fields treated with metam-sodium. Department of Pesticide Regulation, Sacramento Pesticide Regulation Document No 50150-151, Rec No. 170403, Sacramento, CA

Sullivan DA, Holdsworth MT, Hlinka DJ (2004) Control of offgassing rates of methyl isothiocyanate from the application of metam-sodium by chemigation and shank injection. Atmos Environ 38: 2457-2470

Thongsinthusak T (2003) Estimation of exposure of persons in California to methyl isothiocyanate. Worker Health and Safety Branch, Department of Pesticide Regulation, Sacramento, CA. HS-1806. 82 pp

USEPA (2005a) Overview of the use and usage of soil fumigants. Office of Pesticide Programs, Biological and Economic Analysis Division (7503). Federal Register Environmental Documents, US Environmental Protection Agency

USEPA (2005b) Metam sodium: Revised HED human health risk assessment for phase 3: DP barcode: D318051, Metam Sodium PC Code: 039003, MITC PC Code: 068103. Federal Register Environmental Documents, US Environmental Protection Agency 